\title{
La intervención estatal en los movimientos territoriales post-2001 en Argentina
}

\author{
A intervenção do Estado nos movimentos territoriais \\ pós-2001 na Argentina \\ State intervention in the post-2001 territorial movements \\ in Argentin
}

\section{Carolina Mamblona* Lorena Ugarte**}

\begin{abstract}
Resumen - En el presente artículo, nos proponemos sintetizar el derrotero de los movimientos territoriales post-2001, identificando específicamente al movimiento de trabajadores desocupados perteneciente al tercer anillo del conurbano bonaerense o Gran Buenos Aires. Se recupera un balance al respecto de lo ocurrido en las jornadas del 19 y 20 de diciembre de 2001, hito fundamental del período de resistencia al neoliberalismo, en su implementación más aguda de la década de los 90' para comprender la intervención estatal producida a partir del 2003 del gobierno de Néstor Kirchner. Queremos resaltar el retorno a una matriz de tipo nacional popular en la intervención territorial ocupando el espacio social "abierto" por las organizaciones de desocupados autónomas (autonomía con respecto al Estado y a las formas tradicionales de ejercicio político, incluyendo diversas experiencias o tradiciones que actúan en conjunto con sectores de la matriz nacional popular volcados a la lucha anti-neoliberal) quienes pierden su fuerza unificada, fragmentándose y relegando espacios a la política tradicional. Por último, hacemos mención a estrategias de implementación territorial del período y sus consecuencias para la intervención profesional del trabajo social.
\end{abstract}

Palabras clave: movimientos sociales; territorio; Estado.

Resumo - No presente artigo, propomos sintetizar o percurso dos movimentos territoriais pós-2001, identificando especificamente o movimento de trabalhadores desempregados pertencente ao terceiro anel da conurbação da Província de Buenos Aires ou Grande Buenos Aires. O artigo recupera a análise do ocorrido nas jornadas de 19 e 20 de dezembro de 2001, marco fundamental do período de resistência ao neoliberalismo, na sua implementação mais aguda da década dos

\footnotetext{
* Docente adjunta de la Cátedra de Trabajo Social V. Coordinadora del Área de Investigación: Movimientos Sociales, conflictividad social y Trabajo Social, en la Facultad de Trabajo Social de la Universidad Nacional de La Plata (FTSUNLP). Correspondência: Calle Constitución no 4170 1a piso, departamento 27-Ciudad Autónoma de Buenos Aires, República Argentina. Código Postal (CP 1264). E-mail: <cmamblona@yahoo.com.ar>.

** Docente auxiliar de la Cátedra de Trabajo Social V. Integrante del Área de Investigación: Movimientos Sociales, conflictividad social y Trabajo Social, en la Facultad de Trabajo Social de la Universidad Nacional de La Plata (FTSUNLP). Correspondência: Calle 147 esq. 522 nº 998 - La Plata, República Argentina. Código Postal (CP. 1900). E-mail: <el_ugarte@yahoo.com.ar>.
} 
1990 para compreender a intervenção estatal produzida a partir de 2003 no governo de Nestor Kirchner. Queremos ressaltar o retorno a uma matriz de tipo nacional popular na intervenção territorial ocupando o espaço social "aberto" pelas organizações de desempregados autônomas (autonomia com respeito ao Estado e às formas tradicionais do exercício político, incluindo diversas experiências ou tradições que atuam em conjunto com setores da matriz nacional popular voltados à luta anti-neoliberal) as quais perdem sua força unificada, fragmentando-se e relegando espaços à política tradicional. Por último fazemos menção às estratégias de implementação territorial do período e suas consequências para a intervenção profissional do serviço social.

Palavras chave: movimentos sociais; território; Estado.

\begin{abstract}
In this paper, we propose to synthesize the course of the post-2001 territorial movements, specifically identifying the movement of unemployed workers that belongs to the suburban third ring of the Argentinean capital city or "Big Buenos Aires". We make a balance of what happened during the days of December the 19th and 20th of 2001 , the fundamental milestone of the period of resistance to neoliberalism in its most acute implementation during the 90 s, to understand the state's intervention produced from 2003 in Nestor Kirchner's government. We want to highlight the return to a "popular national" matrix in the territorial intervention, occupying the social space "opened" by unemployed workers' autonomous organizations (autonomy in respect to the State and the traditional forms of political exercise, including diverse experiences or traditions that act together with segments of the "popular national" matrix turned to the anti-liberal struggle), who lost their unified strength, fragmenting and relegating spaces to the traditional politics. Finally, we mention territorial implementation strategies of the period and their implications for the professional intervention of social work.
\end{abstract}

Keywords: social movements; territory; State.

\title{
Jornadas del 19 y 20 de diciembre de 2001: el "argentinazo"
}

La inflexión en la relación de fuerzas en 1989-1990 sobre la base de la amenaza hiperinflacionaria, su consolidación con la emergencia de un consenso en torno al programa neoconservador de salida de la crisis y la cristalización de este consenso en el apoyo a la 'estabilidad' a partir del lanzamiento de la convertibilidad en abril de 1991, posibilitaron la ofensiva del capital entre 1992 y 1995, que transformó radicalmente el modo de la acumulación y su corazón: las formas concretas de explotación de la fuerza de trabajo. A su vez, esta trasformación de las formas de explotación y de las condiciones de acumulación de capital completó la coerción hiperinflacionaria con la amenaza del desempleo y la fragmentación de la clase obrera, lo que indujo a la aceptación de la ofensiva del capital en los lugares de trabajo. (PIVA, 2009, p.22).

Las medidas económicas implementadas por los gobiernos de Menen (1989-1999) y De la Rúa (1999-2001) dejarán el saldo más negativo para la clase trabajadora que se verá amenazada por la desocupación y por la precarización más alta desde que se implementara el modelo neoliberal introducido por la última dictadura cívico-militar. (1976-1983) 


\section{ReVistg all paUtg}

\} LA INTERVENCIÓN ESTATAL EN LOS MOVIMIENTOS TERRITORIALES - MAMBLONA, C. A.; UGARTE, L. \}

Pero estos cambios no se produjeron sin resistencias, siendo la década de los $90^{\prime}$ años de protestas muy significativas que tuvieron como protagonistas a jubilados y trabajadores estatales resistiendo a los despidos, privatizaciones y recortes en salud y educación, así como a estudiantes luchando contra el modelo privatista en las universidades y escuelas secundarias. También formarán parte de estas luchas, el movimiento de derechos humanos, el movimiento anti-represivo y nuevas agrupaciones como $\mathrm{HI}$ JOS. ${ }^{1}$ En ese contexto de disputa callejera, emergerán los movimientos de trabajadores desocupados, cuyas características centrales serán: la acción directa a través del corte de rutas para interrumpir la circulación de la producción; democracia interna, a través de las asambleas, cabildos u otras formas colectivas de toma de decisiones; trabajo territorial implementando comedores, merenderos, huertas, proyectos productivos, para paliar la crisis y la implementación de diversos planes sociales conquistados en la disputa con los distintos gobiernos.

Como corolario de una década de luchas, coincidimos con Nicolás Iñigo Carrera y María Celia Cotarelo $(2002,2006)$ cuando afirman que desde 1993 hasta 2002 se consolida un ciclo ascendente de la protesta social en nuestro país, caracterizándolo como un proceso que se abrió con la pueblada de Santiago del Estero (Santiagazo 1993) y que se cierra luego de las jornadas de 2001. En este período las formas de organización van adquiriendo mayor sistematicidad dejando el escenario local - donde emergieron - para alcanzar sistematicidad y protagonismo a nivel nacional. Para estos autores las jornadas del 2001, que contienen todas las formas de lucha desplegadas en la etapa, se pueden caracterizar como una insurrección espontánea que nuclea y moviliza a diversas capas sociales bajo la consigna "que se vayan todos", enfrentando así al gobierno (De la Rúa, 1999-2001) e impugnando a la clase dominante en general.

La magnitud de lo ocurrido en diciembre de 2001 es resultante de la simultaneidad y articulación de las distintas acciones de los diferentes sujetos, hasta constituir uno nuevo. Se trata de un proceso que comienza con las movilizaciones convocadas por las centrales obreras y organizaciones de pequeños y medianos empresarios, continúa en la huelga general, cortes de rutas, saqueos, manifestaciones y lucha callejera, ataques a edificios públicos, bancos y empresas privatizadas y cacerolazos, hasta culminar en el combate callejero en el centro político del país. (COTARELO; IÑIGO CARRERA, 2006, p. 88)

Se recogen diversas denominaciones para caracterizar a estas jornadas y procesos que desembocaron en diciembre de 2001, tales como:

\footnotetext{
${ }^{1}$ HIJOS es una organización de los hijos de personas desaparecidos y exiliados por razones políticas que nació en los 90. Su relevancia estuvo dada entre otros aspectos, por su método de lucha, el escrache. El mismo implicó marcar o "escrachar" las casas de represores y cómplices de la última dictadura que hasta ese momento no habían sido juzgados. Surge esta modalidad de acción directa, bajo la consigna: "Si no hay justicia, hay escrache".
} 


\section{hevigta pll paעtg}

\} LA INTERVENCIÓN ESTATAL EN LOS MOVIMIENTOS TERRITORIALES - MAMBLONA, C. A.; UGARTE, L. \}

rebelión, jornadas revolucionarias, jornadas destituyentes, estallido, etc., siendo una de las denominaciones de mayor consenso y que se enlaza con la historia de lucha de la clase obrera de los 70' (Cordobazo, Rosariazo, etc), la de entenderlas como "argentinazo".

Coincidimos con los mencionados autores en que se trató de una insurrección espontánea ${ }^{2}$, dado que las dos condiciones necesarias para identificarla como insurrección consciente no estuvieron desarrolladas. Estas son, que no sólo exista disposición a la lucha por derribar el poder político de la clase dominante, sino que también actúe una o un conjunto de organizaciones políticas en unidad preparadas (teórica-prácticamente) para dirigir a las masas populares. En tanto el componente de clase media presente en la rebelión, no buscó prolongar un estado cuasi anárquico por tiempo indeterminado, sino que impugnaban a la clase política pero querían reconstituir rápidamente acciones democráticas, estatizantes, aunque con tintes antiimperialistas, pero propios de la emancipación política. Las clases medias organizados en las asambleas barriales de las principales ciudades y ahorristas cuyos fondos fueron confiscados, también coexistieron con otros sectores clasistas cuyo horizonte era construir un "cambio social" de raíz.

Aún sin haber producido un cambio político sustancial, la importancia de estas jornadas de diciembre de $2001^{3}$ - siendo un hito alto de la lucha de clases - radica en la experiencia concreta de tensionar al poder político dominante hasta el punto de lograr la renuncia de cinco presidentes en el lapso de una semana. En simultáneo se experimentó como aprendizaje colectivo, la falta de organización y centralización de los sectores subalternos, dando lugar a prácticas espontaneístas de matriz autonomista, ${ }_{1}^{4}$ e intervenciones políticas orientadas por un anticapitalismo romántico que si bien apuntaba a "que se vayan todos", no lograba anticipar la reacción y reconfiguración de las clases dominantes.

Durante el corto mandato de Duhalde en la presidencia de la Nación (enero de 2002 a mayo de 2003), la criminalización de los movimientos sociales se convierte en un complemento imprescindible del clientelismo político. Su estrategia de recomposición de la gobernabilidad, comprende la agudización de la concentración económica en manos de los sectores financieros, junto a una drástica pérdida del poder adquisitivo y el avance de la pobreza estructural dejando a millones de familias en la pobreza e indigencia. El índice de desocupación pasa a ser el más alto de la

\footnotetext{
2 Para los autores la Insurrección espontánea presenta rasgos característicos como: " 1) la muchedumbre en la calle, 2) no organizada, 3) que espontáneamente levanta barricadas; 4) dando lugar a una lucha de calles 5) en que las masas pasan por encima de las organizaciones." (IÑIGO CARRERA N.; COTARELO, 2003, p.300)

${ }^{3}$ El saldo para el pueblo, implicó más de 35 muertos y cientos de heridos en las Jornadas del 19 y 20.

${ }^{4}$ Se caracterizan por envilecer los análisis sobre el Estado buscando una posición que concibe un cambio que se realizará por fuera del Estado, autónomamente. Son referencias las obras de Negri y Hardt (2000), Virno (2003) y Holloway (2002) con sus respectivas concepciones teórico-políticas. En Argentina se desarrollaron estas ideas al calor del 2001, en los análisis del Colectivo Situaciones.
} 
etapa, siendo en octubre de 2001 del $18.3 \%$, llega al $21.5 \%$ en mayo de 2002 y entre el 23 y $24 \%$ durante algunos meses críticos del año $2003^{5}$.

El uso clientelar de la asistencia estatal por parte del aparato político del Partido Justicialista se transformó en el principal mecanismo de control social, profundizando la dependencia a las estructuras del Estado y consolidando el agravamiento de las condiciones de vida aunque paradojalmente sea el momento de "engorde" ${ }^{6}$ de las organizaciones según la expresión de Svampa (2008).

En estas condiciones se llega a las Jornadas del 26 de junio de 2002 en Puente Pueyrredón (Avellaneda). Para todos los movimientos de trabajadores desocupados dicha jornada, tenía una importancia especial. Se había logrado reunir al conjunto de organizaciones que por entonces conformaban el heterogéneo movimiento "piquetero", reclamando: pago de los planes de empleo, que hacía meses se habían dejado de percibir; aumento de los subsidios de 150 a 300 pesos; implementación de un plan alimentario bajo gestión de los propios desocupados; insumos para las escuelas y los centros de salud de los barrios; desprocesamiento de los luchadores sociales y el fin de la represión.

La protesta de más de tres mil manifestantes en el Puente Pueyrredón ${ }^{7}$ fue cercada por un operativo represivo que reunió a más de 400 efectivos de las tres fuerzas federales (Gendarmería, Prefectura y Policía Federal) junto a la Policía Bonaerense, inaugurando una actuación conjunta.

El resultado fue trágico, la muerte de dos militantes "piqueteros", Darío Santillán y Maximiliano Kosteki, junto a un centenar de heridos, muchos de gravedad y con balas de plomo. Esto implicó el adelantamiento de las elecciones para lograr una salida que permitiera la gobernabilidad.

El 3 de julio de 2002, se realizó una marcha multitudinaria en repudio a la denominada "Masacre de Avellaneda", donde diversos sectores de la sociedad, reclamaron justicia y pusieron en evidencia la trama de impunidad del gobierno de Duhalde. Esta iniciativa marcó un límite a las acciones de criminalización a las organizaciones "piqueteras" desbaratando los intentos del gobierno que buscaban culpabilizar a las víctimas. Podemos decir, que en esta etapa:

Se consolidaba así una nueva generación militante, la de 2001, articulada sobre la territorialidad, el activismo asambleario, la demanda de autonomía y la horizontalidad de los lazos políticos. Un ritual de viaje los unía en todo el país: el recorrido territorial que iba del centro de la ciudad hacia la periferia, en especial, aquellos que

\footnotetext{
${ }^{5}$ Construcción de diversas fuentes en: Tesis de Maestría Mamblona, Carolina, FTS-UNLP (2012)

${ }^{6}$ Se trata de la administración de planes sociales que los movimientos de trabajadores desocupados logran obtener con la lucha, llegando entre todas las organizaciones juntas (alrededor de 50 a nivel nacional) a administrar sólo el $10 \%$ sobre un total de 2.200.000; el resto de los planes se implementaron a través de las redes municipales .El principal programa es el Jefas y Jefes de Hogar Desocupado, creado en 2002 (Dec. 565/02), con una ayuda económica, no remunerativa de $\$ 150$ para el jefe o jefa de hogar desocupado mayor de 18 años.
} 
iban hacia los lugares más pobres del conurbano bonaerense. El desafío tenía como corolario la necesidad de la construcción "desde abajo" y la exigencia de la articulación entre política y ética. "Maxi y Darío", quienes en definitiva habían ofrendado su vida en el peor momento de la crisis, aparecían como "modelos ejemplares" para esa nueva juventud militante. (SVAMPA, 2011, p.22 - destaques originales).

\section{La intervención estatal sobre los movimientos territoriales (2003-2007)}

En el marco del primer gobierno de Kirchner asistimos a una "restauración de ciertos derechos ya conquistados, pero no obtención de logros primarios", donde "la sucesión de gobiernos Kirchner [...] reconstruyó el poder de las clases dominantes, otorgando concesiones sociales y democráticas" (KATZ, 2010). Se trata de una recomposición burguesa con otorgamiento de concesiones, para lograr una hegemonía política y cultural que aquiete las aspiraciones del 2001.

Varios autores denominan este proceso, como una política de corte neo-desarrollista que "manifiesta más claramente una impronta de desarrollo capitalista periférico buscando consolidar la posición de los grandes capitales regionales (de base trasnacional) como proveedores de materias primas y manufacturas de bajo contenido tecnológico" (FÉLIZ, 2011, p.258). El índice de desocupación descendió hasta constituirse en un dígito, estimado alrededor de entre el 7 y $9 \%$, sin que recuperen los guarismos de inicios de los '80, y aunque expresa una mejoría, esto sólo es posible de la mano del aumento del trabajo precarizado ${ }^{8}$; perviviendo aún en el horizonte de la sociedad argentina, el problema de la desocupación. Se trata de un proceso de "reprimarización" de la economía, centrado en lo que Svampa (2008) denominó como modelo extractivista exportador ya que se genera un superávit fiscal con un colchón de dólares provenientes de la exportación de soja y minerales.

Según refiere la autora, la política de masificación de la ayuda social iniciada durante el gobierno de Duhalde continuó bajo la presidencia de N. Kirchner, quien retomó la iniciativa de

Recuperar el espacio perdido por el peronismo en manos de las nuevas organizaciones de tipo territorial. Así, la política asistencial fue la

\footnotetext{
${ }^{7}$ Uno de los puentes que une la capital federal con la Provincia de Buenos Aires.

${ }^{8}$ Resulta emblemática la muerte del militante Mariano Ferreyra (octubre de 2010) Se realizaba un plan de lucha de los trabajadores terciarizados despedidos, desde hacía ya tres meses, contra la empresa privatizada a cargo del transporte ferroviario. El joven de 23 años quien acompañaba a los despedidos, fue asesinado por patotas al mando del dueño de dicha empresa y a su vez delegados gremiales del sindicato ferroviario "La Fraternidad", quienes actuaron al amparo policial que liberó la zona.
} 
punta de lanza para "demonizar" a las organizaciones piqueteras y apuntar a su flanco más débil (la dependencia respecto del Estado), acusándolas de supuestos manejos clientelares y manipulación política. (SVAMPA, 2008, p.49).

Se trató de una intervención espacial y política acompañada de la táctica inicial de la transversalidad, ${ }^{9}$ luego dejada de lado en post de volver a apostar a las formas más clásicas de construcción política a través del partido de gobierno (justicialista) y los sindicatos tradicionales (que apoyaron los despidos masivos y recortes estatales en los $90^{\prime}$ ) y centrales como la CGT (Confederación General del Trabajo). Esta política denominada cooptación, ofreció a sectores del movimiento piquetero, organismos de derechos humanos y organizaciones de trabajadores rurales, que participaran en el ámbito estatal, a cambio de incluirse en proyectos políticos y programas sociales que sustenten y amplíen la gestión estatal.

Se mostraron decididos a construir alianzas con parte de los nuevos actores, a condición de que moderaran la modalidad y frecuencia de sus protestas, y asumieran un grado de compromiso con la gestión pública. (CAMPIONE; RAJLAND, 2006, p.303)

Se incorporan militantes en cargos legislativos o de gestión ejecutiva con el objetivo de "formar actores territoriales, es decir de sujetos políticos activos, conjuntamente con redes organizativas" (MARIFIN, 2011). De esta manera se agregan referentes de organizaciones "piqueteras", de derechos humanos, militantes de género, organizaciones campesino-indígenas, militantes territoriales en cargos estatales de distintos niveles de gobierno, reconfigurando la acción política de sus organizaciones. ${ }^{10}$

Si bien el término cooptación pudo graficar la incorporación de los referentes y organizaciones al gobierno, en los primeros tiempos, también supone una concepción de sujeto asimilado pasivamente, quedando estrechos márgenes de conciencia en la decisión de los mismos. Lo que deja en evidencia es que no se trata de movimientos cooptados, sino de cooptación o llegada al gobierno de algunos dirigentes que empeñan desde concepciones verticalistas a la propia organización, desde la cual se posicionaron, en una disputa o relación de fuerza. Esto conecta a algunas de las organizaciones que ocuparon el escenario de la lucha hasta el 2002 con las prácticas más tradicionales del partido justicialista que reactualizan, en términos de Svampa (2011) por la propia identidad peronista del pueblo, la matriz nacional popular; recuperando así el espacio perdido en el territorio.

\footnotetext{
${ }^{9}$ Transversalidad se refiere a la articulación con diversas organizaciones y movimientos sociales que no necesariamente provenían de la estructura formal del peronismo aunque sus bases se reconozcan peronistas.

${ }^{10}$ Entre las organizaciones podemos nombrar a Barrios de Pie; Movimiento de trabajadores desocupados "Evita"; Federación de tierra, vivienda y hábitat (FTV); fracción del MTD Aníbal Verón; Quebracho; Movimiento de Unidad popular (MUP); sectores del Mocase; militantes de género hoy Diputadas después de la sanción de la ley de matrimonio igualitario en 2010, entre otros.
} 


\section{hevigta pll paעtg}

\} LA INTERVENCIÓN ESTATAL EN LOS MOVIMIENTOS TERRITORIALES - MAMBLONA, C. A.; UGARTE, L. \}

Se trata de una incorporación política que como, fuera expresado más arriba, es a cambio de moderar la protesta e implica el acceso a un abanico de recursos económicos de los diversos programas y políticas sociales, a los que no accederán los sectores que persisten en la lucha y cuyas organizaciones tienen construcciones con importantes grados de democracia interna en la toma de decisiones colectivas. ${ }^{11}$

Otras de las tácticas que grafica este proceso fue el traspaso del Plan Jefes y Jefas de Hogar Desocupados, implementado desde 2002, a diversos planes. Este traspaso iniciado en 2006, implicó segmentar a la población en dos categorías, "empleables" e "inempleables" de acuerdo a su trayectoria y capacitación laboral. (SEIFFER, 2010)

Los "empleables" fueron destinatarios del Programa Seguro de Capacitación y Empleo dependiente del Ministerio de Trabajo, Empleo y Seguridad Social, centrado en la capacitación y realización de actividades de formación y búsqueda laboral para "salir del asistencialismo". El mismo implicaba obtener un subsidio no remunerativo y no contributivo, y los beneficiarios pasaban a integrar por ello las filas de los trabajadores ocupados cuya duración máxima se podía extender en 24 meses. Mientras que los "inempleables" fueron destinatarios del Plan Familia por la Inclusión Social, dependiente del Ministerio de Desarrollo Social. El Plan Familias pasaba a intervenir sobre la figura de la mujer de la "familia piquetera", fortaleciendo desde un rol tradicional la responsabilidad reproductiva e impidiendo la mediación de las organizaciones sociales con los destinatarios.

Esto debilitó la capacidad de control de las organizaciones respecto a esta cobertura social, fortaleciendo el papel del Estado. La política de Kirchner apuntó a encapsular a las organizaciones "piqueteras" críticas y reorientar los recursos hacia organizaciones "piqueteras" que apoyaran el proyecto político nacional. Hacia inicios del 2007 según el Informe de Gestión (2006 - mayo de 2007 del Ministerio de Desarrollo Social de Nación), 450.000 personas del Plan Jefas y Jefes de Hogar Desocupado habían sido incorporadas al Programa Familias por la Inclusión Social.

Se combina una fragmentación de las políticas sociales con la focalización de los programas sociales. Se multiplican los programas, desarmando el universo de los desocupados que hasta el momento habían actuado - a pesar de sus diferencias - con importantes grados de unidad.

Entre las herramientas de intervención que el gobierno desplegó en el territorio, destacamos algunas como:

- Plan de Desarrollo Local y Economía social "Manos a la obra", lanzado el 11 de agosto de 2003. "El plan provee recursos (herramientas de trabajo, las máquinas, los insumos, los bienes de capital) a los sectores

\footnotetext{
${ }^{11}$ Justicia Ya para derechos humanos; Frente de Organizaciones en Lucha (FOL); Frente Popular Darío Santillán (FPDS); Partido Obrero (PO); Corriente Clasista y Combativa (CCC); Movimiento de trabajadores desocupados Aníbal Verón (MTD AV), Movimiento Teresa Rodríguez (MTR), entre otros como expresiones de movimientos territoriales.
} 


\section{hevistg ell paUtg}

\} LA INTERVENCIÓN ESTATAL EN LOS MOVIMIENTOS TERRITORIALES - MAMBLONA, C. A.; UGARTE, L. \}

de escasos recursos para conformar emprendimientos productivos, a la vez que brinda capacitación y asistencia técnica (...)." Se desarrolla una

Variedad de experiencias asociativas que comprenden a emprendimientos productivos de la economía social unipersonales, familiares, de autoconsumo y los asociativos comerciales. (...) Atender las necesidades de estas experiencias es de suma importancia para la inclusión social, ya que en los últimos años se han constituido como respuesta frente a la exclusión del mercado de trabajo de vastos sectores (...), inclusive en varios momentos se constituyeron como ámbitos de contención social frente a la crisis (KIRCHNER, 2007, p.194)

Dentro de este programa se desarrollan otros dentro de lo que se denominan "estrategias de economía social", como: Marcas Colectivas; Microcréditos financiados por el Banco de la Buena Fe, Fondo de capital Social y programa de promoción del Microcrédito.

Todas estas acciones se enmarcan en la ley del microcrédito 26.117, sancionada en 2006.

- 2005: Centros Integradores Comunitarios (CIC) que "expresan una concepción de trabajo interdisciplinario, intersectorial y participativo, para el desarrollo y profundización de acciones de promoción social y prevención socio-sanitaria". Se realiza a partir de la acción conjunta de los ministerios de Desarrollo Social; Salud; Planificación Federal; Inversión Pública y Servicios; y Trabajo, Empleo y Seguridad Social. Resulta significativo que: "en una primera etapa, la construcción de los CIC estuvo a cargo de 845 cooperativas conformadas, cada una de ellas, por destinatarios del Programa Jefas y Jefes de Hogar Desocupado" (Informe de Gestión Ministerio de Desarrollo Social 2006-2007)

- Registro Nacional de efectores "Monotributo Social". El objetivo es otorgar un beneficio a una nueva categoría tributaria para la población socialmente vulnerable, que esté realizando actividades dentro de la economía social, que por este "régimen especial de Monotributo los inscriptos puedan emitir facturas constituyéndose en proveedores de empresas públicas o privadas, y obtener cobertura médica a través de una Obra social, a elección del beneficiario" (Informe de Gestión Ministerio de Desarrollo Social 2006-2007).

- Plan Nacional de Seguridad Alimentaria: este plan nacional aporta al derecho a la seguridad alimentaria a través del uso de tarjetas magnéticas o tickets permitiendo a las familias realizar sus propias compras. A comienzos de 2007, 686.017 familias recibieron tickets o tarjetas y 630.463 módulos alimentarios. Desde este plan se asiste a comedores, se entrega alimentos a 923 organizaciones, marcando como un logro del programa la reducción de 2300 a 1800 comedores entre 2006-2007. En conjunto con el Instituto de Tecnología Agropecuaria (INTA) se fomenta el 


\section{hevigta pll paעtg}

\} LA INTERVENCIÓN ESTATAL EN LOS MOVIMIENTOS TERRITORIALES - MAMBLONA, C. A.; UGARTE, L. \}

Pro-Huerta y estrategias de capacitación para que cada familia produzca sus alimentos (Informe de Gestión Ministerio de Desarrollo Social 20062007).

Todas estas intervenciones en el territorio implicaron que lo territorial pasara a formar parte de un componente central de las diversas políticas sociales para disputar y reconquistar el espacio que habían perdido los partidos tradicionales - especialmente el partido justicialista - con sus referentes locales en manos de las organizaciones autónomas, forjadas al calor de la lucha de finales de los 90' y del 2001.

Para trabajar sobre la dimensión territorial incorporaron un discurso que concibe al territorio de manera homogénea, sin conflictos y creyendo que desde la dimensión comunitaria se abordarán los problemas y necesidades que surgen "en" y "desde" lo local, desvinculando análisis políticos y económicos más generales. El concepto de territorio que acuñan se corresponde con la idea de barrio concebido como comunidad (CRAVINO, 2002), donde se disuaden los conflictos y tensiones de clase y lucha por el poder. Tal como se manifiesta en el documento La Bisagra del Ministerio de Desarrollo Social de Nación, la concepción es la de "participación ciudadana", entendiendo a la misma como: "la posibilidad de contribuir a la vida pública de la comunidad a través de la participación" (KIRCHNER, 2007, p.142)

Apelar a la comunidad refiere a un proceso complejo donde se obliga a las organizaciones de base territorial a estructurar su acción con responsabilidad jurídica a través de la obtención de personería; actuación en redes y responsabilizarse de los diversos aspectos de la gestión gubernamental. También el fracaso de las acciones, es adjudicado a las organizaciones reproduciendo desde una esfera moralizante - anclada en el éxito o fracaso de las mismas - una visión idealizada de la "comunidad".

Tal como se evidencia en el Documento del Ministerio de Desarrollo Social de Nación:

mientras se desintegraban los lazos sociales, coexistieron distintos sectores de la sociedad que generaron un abanico importante de acciones en el territorio: organizaciones sociales, movimientos de trabajadores desocupados, movimientos barriales, sectores eclesiásticos (entre otros) que, en la búsqueda por abordar las necesidades de quienes se encontraban excluidos, recrearon modos distintos de participación. Críticos de la situación en la que se encontraban, se apropiaron de muchos de los programas destinados a "compensar" y "aliviar" la pobreza, redefiniéndolos en su propio territorio. (Construcción Participativa del Estado, 2009)

La construcción del Estado pasa a ser una responsabilidad de todos, organizaciones y responsables políticos por igual. Aquellas organizaciones identificadas partidariamente son las depositarias de las acciones 


\section{hevistg ell paUtg}

\} LA INTERVENCIÓN ESTATAL EN LOS MOVIMIENTOS TERRITORIALES - MAMBLONA, C. A.; UGARTE, L. \}

estatales. De esta manea queda velado que las organizaciones que no se alinean al gobierno, no pasan a ser parte de programas o de la gestión de los mismos en el nivel territorial, siendo apartados de la asignación de recursos, con lo cual no podremos hablar de participación igualitaria. Resulta Ilamativo que los trabajadores sociales de la órbita del Ministerio de Desarrollo Social de Nación en muchas situaciones en su labor en territorio tienen que "depender" de referentes políticos locales para intervenir profesionalmente siendo delimitados y orientados, en cuanto a los destinatarios o sectores del barrio con los que se trabajará. Esto desliza criterios profesionales, que no deben ser ni restrictivos ni presuponer una orientación política determinada.

Las políticas sociales de focalización territorial invocan la importancia de la participación de la comunidad en proyectos, en decisiones políticas, en el diseño de políticas sociales, en la implementación de leyes, etc. En pos de esto, se descentralizan acciones nacionales y/o provinciales, pasando el municipio a tener un protagonismo estatal, legitimándose y recuperando el control del territorio. Las mesas de gestiones barriales y/o regionales son la forma de articulación estatal, fortaleciendo la corresponsabilidad y desdibujando la responsabilidad del estado en la manutención de la desigualdad como principio organizador de la sociedad.

El estado abarca desde la estrategia territorial todas las áreas de intervención en lo social, como salud; vivienda; educación y asistencia social. Por ello se incorpora en diversas leyes (ley de Niñez Nacional 26.061: 2005; Ley de Niñez Pcia. Bs As 13.298: 2005; Ley Nacional de violencia contra las mujeres 26.485; Ley nacional de salud mental 26.657) un discurso que apela al compromiso de los actores comunitarios en la figura de la corresponsabilidad en la resolución de problemas.

Así se reconvierte el descreimiento a la clase política, con la impugnación que tuvo en 2001, reforzando al barrio como el espacio privilegiado para la actividad social y política, revistiendo a lo social en un simulacro de participación y encubriendo nuevas formas de tutelaje paternalista.

Se trata de homogenizar a los pobladores de un barrio, eliminando el conflicto de la escena, buscando reintroducir un aspecto de la praxis política, centrado en preocupaciones de tipo democráticas, desvinculadas del "cambio social" al que se aspirara en la década precedente.

Aunque ambas se reivindiquen herederas de la generación del 70, la militancia kirchnerista apunta a la revaloración del rol del Estado y combina una buena dosis de pragmatismo político con las clásicas apelaciones a lo nacional-popular (en las que se incluye la defensa del líder como expresión y condensación del proyecto político); mientras que la generación de 2001 reivindica el carácter más genuino del trabajo basista y territorial, y en los casos de la narrativa autonomista, continúa manteniendo una relación conflictiva (aunque no 
exenta de debates) con la visión de una construcción política desde el Estado". (SVAMPA, 2011, p. 25)

Aquel ethos militante producido al calor de aquellos procesos colectivos, se reconvierte y reactualiza en un ethos de tipo nacional popular que reagrupa el escenario político combinando dosis de política tradicional con recursos estatales y pragmatismo político.

\section{Conclusión}

La convocatoria a intervenir en aspectos que suponen procesos homogéneos de sociabilidad, significa desplegar prácticas que promuevan la participación de todos y todas, incentiven relaciones solidarias entre vecinos por medio de la ayuda mutua, como así también la vuelta por establecer una conexión cara a cara entre los integrantes de un mismo barrio, que identifiquen los problemas comunes, establezcan instancias de diálogo, valoricen los saberes y desarrollen proyectos comunitarios tendientes a resolver problemas sociales que tienen su causa en las políticas neoliberales de la década de los 90. Este idealismo que contiene "lo comunitario" como dimensión recortada de la práctica del trabajo social, niega la totalidad de los procesos sociales, encubre la historia de las últimas décadas, borra el conflicto y la lucha de intereses en los territorios que son disputados por su condición (sean zonas inseguras, organizadas por alguna agrupación social, olvidadas por las instituciones estatales, de interés económico por su ubicación, etc.) e impidiendo analizar la política que se entrelaza en cada lugar, teniendo así poco margen para la problematización de la intencionalidad profesional en ciernes. Todo esto a cargo de los profesionales, técnicos o estudiantes no solo de trabajo social, sino de las ciencias sociales en general que deben garantizar la concreción del discurso integrador y universal que potencialmente conlleva cada programa social.

La universalidad puede estar garantizada desde esta lógica, en la obtención individual de programas provenientes de distintas áreas, percibiendo bajos montos que no alcanzan a cubrir la canasta básica de alimentos, pero que dan la impresión de estar incluidos por parte del estado en sus políticas sociales dirigidas a los más necesitados, promoviendo una economía de consumo pero sin verdadera movilidad social ascendente. A su vez, la cantidad de programas sociales de corto alcance que conviven en la atención asistencial, exigen para su obtención, la justificación continúa sobre la situación de "vulnerabilidad social" de la persona inscripta, quien busca garantizar un ingreso aunque magro, mediante la obtención de un subsidio, complemento alimentario, etc.

Así planificada e implementada la política social a la familia desocupada, además ha sido informatizada la población "beneficiaria" no 


\section{hevistg all paUtg}

\} LA INTERVENCIÓN ESTATAL EN LOS MOVIMIENTOS TERRITORIALES - MAMBLONA, C. A.; UGARTE, L. \}

permitiendo al trabajo social contar con elementos para intervenir porque la información no está a disposición; oficialmente no se divulgan los datos y exige un tratamiento de cada situación singular, encubriendo una necesidad que es colectiva. Asimismo ocurre algo interesante en cada municipio en particular que tiene que ver con el repentino cambio en las modalidades de acceso a cada programa, requerimientos formales que cambian sin explicación, cruces de datos de los usuarios/as, programas que dejan cesante a un centenar de personas en forma abrupta o de la misma manera se suspende tal o cual recurso, llegando en algunos casos a interrumpirse en períodos intercalados entre sí, con una clara planificación de la dádiva según la coyuntura social, política y económica. Este mecanismo se sostiene en la descentralización de las políticas sociales a las esferas locales de intervención estatal, con graves consecuencias en la distribución, planificación, implementación, logística etc., de los recursos dispuestos en teoría.

Es menester mencionar que el estado dirige la intervención de los trabajadores sociales con las organizaciones sociales que existan en la zona geográfica que abarque su intervención, explicitando la promoción de la "articulación en red", las mesas de diálogo y la presencia de equipos técnicos en los territorios, que dejen en claro que el estado conoce la existencia de otros actores sociales en los espacios de disputa y que se dispone a acercarles su política, escuchar las demandas y generar propuestas. Así es como la relación de los trabajadores sociales con los movimientos sociales está claramente orientada en este sentido, desprofesionalizando al trabajo social en nombre de la retórica militante.

No queremos dejar de mencionar que en paralelo a la política asistencial hacia el desempleo, el estado llevó a cabo medidas represivas y criminalizadoras de la protesta social. Durante el año 2005 el gobierno obligó a dar aviso y solicitar autorización en caso de llevar adelante una movilización, utilizando a las fuerzas nacionales para controlar cortes de ruta, marchas, etc. A su vez, se enrejaron la mayoría de los edificios públicos para limitar que lleguen a sus puertas, son valladas en primer lugar aquellas que impidan el acceso a la histórica Plaza de Mayo.

La discusión sobre la judicialización de la protesta social tuvo que ver con el ataque al sistema democrático y aunque el gobierno de Néstor Kirchner sostuvo un discurso de no criminalizar y no reprimir,

si se suman los años de gobierno de Carlos Menem y Eduardo Duhalde, se llega a 4 muertes producidas en contextos de protesta social, frente a los 19 ca-sos de muertes producidas durante los años de gobierno del matrimonio Kirchner (GARGARELLA, 2014, p.8).

Tiempo después se avanza en la regu-lación sancionándose en 2011, la Ley Antiterrorista (Ley 26.734), siendo una de las peores legis- 


\section{Revigta pll paUtg}

\} LA INTERVENCIÓN ESTATAL EN LOS MOVIMIENTOS TERRITORIALES - MAMBLONA, C. A.; UGARTE, L. \}

laciones regionales en la materia; lo que implica una amenaza para los manifestantes y para el ejercicio de la expresión política en un claro intento por silenciar los conflictos. Hace pocos meses se vuelve a intentar reglamentar por medio de un proyecto de ley la protesta social, buscando que se pida autorización para los diversos reclamos. ${ }^{12}$

Varios de los mecanismos y políticas analizadas en el primer gobierno de Néstor Kirchner, se consolidan y despliegan con mayor amplitud en los dos gobiernos posteriores de Cristina Fernández de Kirchner y serán objeto de futuros análisis, en virtud de los virajes sobre la economía nacional y su impacto en los trabajadores desocupados.

\footnotetext{
${ }^{12}$ El Frente para la Victoria (FPV) presentó un proyecto de ley para regular las protestas sociales. La iniciativa, que responde a la solicitud realizada por la presidenta Cristina Fernández, tiene como fin regular la convivencia en las manifestaciones públicas. El diputado autor de la iniciativa, aseguró que "no criminaliza, no aplica penas ni sanciona pero sí regula" las demostraciones callejeras. (Diario Tiempo Argentino 17-04-14)
} 


\section{hevistg all paUtg}

\} LA INTERVENCIÓN ESTATAL EN LOS MOVIMIENTOS TERRITORIALES - MAMBLONA, C. A.; UGARTE, L. \}

\section{Referências}

CAMPIONE, D.; RAJLAND, B. Piqueteros y trabajadores ocupados en la Argentina de 2011 en adelante. Novedades y continuidades en su participación y organización en los conflictos. In: CAETANO, G. (Comp.) Sujetos sociales y nuevas formas de protesta en la historia reciente de América Latina. Buenos Aires: CLACSO, 2006.

CRAVINO, C. El Barrio concebido como comunidad: reflexiones acerca de algunos supuestos presentes en la focalización territorial de políticas asistenciales. Artículo presentado en las Jornadas Regionales de Investigación en Humanidades y Ciencias Sociales. Jujuy, 2002, p.75.

COTARELO, M. C.; IÑIGO CARRERA, N. La insurrección espontánea, Argentina diciembre 2001. Descripción, periodización, conceptualización. Doc n. 43. In: Publicación del programa de investigación sobre el movimiento de la sociedad argentina. Documentos y comunicaciones PIMSA AÑO VII-No 7. Documentos de trabajo № 39 a 43. Buenos Aires: 2003.

COTARELO, M. C.; IÑIGO CARRERA, N. Génesis y desarrollo de la insurrección espontánea de diciembre de 2001 en Argentina. In: CAETANO G.; LÓPEZ MAYA, M. (Comp.) Sujetos sociales y nuevas formas de protesta en la historia reciente de América Latina. ISBN 987-1183-64-1. Buenos Aires: CLACSO, 2006.

DOCUMENTO (s/d) Construcción participativa en el Estado. Relato de una Experiencia. Dirección Nacional de Formación de Actores Territoriales. Ministerio de Desarrollo Social de la Nación.

FÉLIZ, M. neoliberalismos, neodesarrollismos, y proyectos contra hegemónicos en suramérica. Conicet. UNLP: 2011, mimeo.

GARGARELLA, R. (2014) Explorar nuevos caminos. In: Le Monde Diplomatique, año XV, № 178. Capital Intelectual, Buenos Aires: 2014.

HARDT, M; NEGRI, A. Imperio. Trad. Eduardo Sadier. Edición de Harvard University Press: 2000. Disponible en: < http://www.chilevive.cl > Acceso en: $3 / 10 / 14$

HOLLOWAY J. Cambiar el mundo sin tomar el poder. el significado de la revolución hoy. México: Universidad Autónoma de Puebla; Buenos Aires: Herramienta, 2002.

INFORME DE GESTION. Políticas sociales en acción. Ministerio de Desarrollo Social de Nación, 2006-Mayo 2007.

KATZ, C. Certezas e incógnitas de la política argentina. A formar filas. La Plata: Guevarista, 2010. 


\section{hevigta pll paעtg}

\} LA INTERVENCIÓN ESTATAL EN LOS MOVIMIENTOS TERRITORIALES - MAMBLONA, C. A.; UGARTE, L. \}

KIRCHNER, A. Políticas sociales en acción. La Bisagra. Memoria/Verdad/ justicia/organización social. Buenos Aires: Ministerio de Desarrollo Social de la Nación, 2003-2007.

MARIFIN, S. E. De hacer piquetes a hacerse en el Estado: un estudio sobre la reconfiguración de la acción política. XII Congreso Argentino de Antropología Social. Buenos Aires: 2011.

MARRO, K. Reflexiones para una comprensión histórico - crítica del movimiento social en sus múltiples dimensiones. In: Debates actuales en trabajo social, mar. 2013. Disponible en: <http://catedralibrets.files.wordpress.com/ 2014/03/marro-k.pdf>. Acceso en: 21 fev. 2014.

SEIFFER, T. La lucha de clases y la política de asistencia en Argentina, 2001 2007. In: Cuestión social, reproducción de la fuerza de trabajo y políticas de asistencia. Publicación de la Carrera de Trabajo Social de la Facultad de Ciencias Humanas-Universidad Nacional del Centro de la Provincia de Buenos Aires. 2010, cap. III, p.49.

SVAMPA, M. Argentina, una década después. Del "que se vayan todos" a la exacerbación de lo nacional-popular. In: Revista Nueva Sociedad, n. 235, sep./oct. 2011, ISSN: 0251-3552. Disponible en: <http://www.nuso.org/ upload/articulos/3794_1.pdf.>. Acceso en: 16 mar. 2013.

Cambio de época. Movimientos Sociales y poder político. Buenos Aires: Siglo XXI, 2008.

Entre la ruta y el barrio. La experiencia de las organizaciones piqueteras. Buenos Aires: Biblos, 2003.

THWAITES REY, M. La autonomía como búsqueda, el Estado como contradicción. Buenos Aires: Prometeo, 2004.

VIRNO, P. Gramática de la multitud. Madrid: Traficantes de Sueños, 2003.

Recebido em 27 de outubro de 2014.

Aprovado para publicação em 25 de novembro de 2014. 